\title{
Evaluation of Metal Powder for Additive MANUFACTURing OF MARAging STEEL
}

\author{
Ivana Zetková, Ludmila Kučerová, Miroslav Zetek, Jiří Česánek, \\ Pavel Hanzl, Milan Daňa, Martin Nozar \& Josef Káňa
}

\begin{abstract}
Regional Technological Institute, University of West Bohemia - Faculty of Mechanical Engineering, Univerzitní 8, 30614 Pilsen, Czech Republic
\end{abstract}
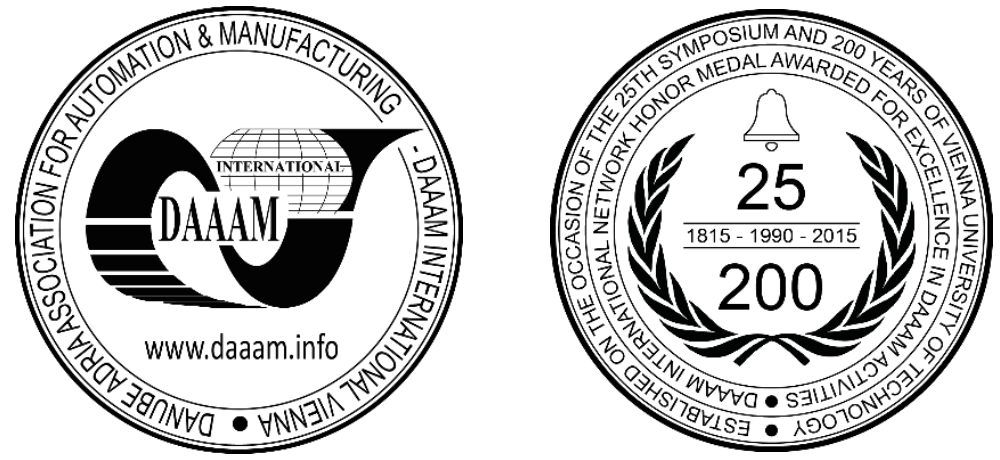

This Publication has to be referred as: Zetkova, I[vana]; Kucerova, L[udmila]; Zetek, M[iroslav]; Cesanek, J[iri]; Hanzl, P[avel] \& Dana, M[ilan] (2017). Evaluation of Metal Powder for Additive Manufacturing of Margaring Steel, Proceedings of the 28th DAAAM International Symposium, pp.0410-0416, B. Katalinic (Ed.), Published by DAAAM International, ISBN 978-3-902734-11-2, ISSN 1726-9679, Vienna, Austria

DOI: $10.2507 / 28$ th.daaam.proceedings.057

\begin{abstract}
Additive technologies enable the creation of complex shapes and structures virtually unattainable using classical production processes. These technologies allow components to be produced not only from paper or plastic, but also from composite materials or metals, with the same or even better properties than their predecessors made by machining or forming technologies. However, for customers who are not specialists in these technologies it may often be difficult to orientate themselves in the wide range of options and take full advantage of the potential of these technologies. As a rule, production process parameters are not as decisive as final product characteristics, especially the price, quality and delivery date. Therefore, this article tries to answer elementary questions that customers might have when considering production using additive technology, and to describe its specifics and possibilities. Special attention is paid to metal 3D printing, whose specifics are illustrated using the example of printing a simple component in various ways, in different quantities and sizes. The article documents an experiment conducted under real conditions using DMLS (direct metal laser sintering) technology, which shows how different ways of printing affect the price, the processing time, and the quality of the final component.
\end{abstract}

Keywords: Additive manufacturing; Metal powder; metallography of the particles; shape of the particles

\section{Introduction}

The input material for additive manufacturing is the powder. There is a wide range of powders available. Each $3 \mathrm{D}$ print machine manufacturer recommends using their "own" powder. The most commonly used materials for laser sintering of metal powder are listed in Table 1. The choice of powder has the main influence on the mechanical properties, functionality and surface quality of the final part. The powders are transported to the users in closed barrels. The powder is taken from the barrels to the dispenser platform in the machine. A recoater applies the defined thickness of the powder on the building platform, where it is melted in the designated area. When the building process is finished, the powder around the sintered parts is sieved back to the dispenser platform for the next process. 


\begin{tabular}{|c|c|c|}
\hline & Material & DIN \\
\hline \multirow{3}{*}{ Aluminium alloys } & AlSi10Mg & 3.2381 \\
\hline & AlSi7Mg & 3.2371 \\
\hline & AlSi12 & 3.3581 \\
\hline \multirow{2}{*}{ Cobalt alloys } & ASTM F75 & 2.4723 \\
\hline & CoCrWC & \\
\hline \multirow{6}{*}{ Tool steels } & AISI 420 & 1.2083 \\
\hline & Marage 300 & 1.2709 \\
\hline & $\mathrm{H} 13$ & 1.2344 \\
\hline & AISI D2 & 1.2379 \\
\hline & AISI A2 & 1.2363 \\
\hline & AISI S7 & 1.2357 \\
\hline \multirow{5}{*}{ Nickel alloys } & Inconel 718 & 2.4668 \\
\hline & Inconel 625 & 2.4856 \\
\hline & Inconel 713 & 2.4670 \\
\hline & Inconel 738 & \\
\hline & Hastelloy X & 2.4665 \\
\hline \multirow{6}{*}{ Stainless steel } & SS 304 & 1.4301 \\
\hline & SS $316 \mathrm{~L}$ & 1.4404 \\
\hline & SS 410 & 1.4006 \\
\hline & SS 440 & 1.4110 \\
\hline & $15-5 \mathrm{PH}$ & 1.4540 \\
\hline & $17-4 \mathrm{PH}$ & 1.4542 \\
\hline \multirow{4}{*}{ Titanium alloys } & $\begin{array}{l}\text { Titanium } \\
\text { Grade } 2\end{array}$ & 3.7035 \\
\hline & Ti6Al4V & 3.7165 \\
\hline & Ti6Al4V ELI & $3.7165 \mathrm{ELI}$ \\
\hline & TiAl6Nb7 & \\
\hline \multirow{2}{*}{ Precious Metal Alloys } & gold & 18 Carat \\
\hline & silver & 930 Sterling \\
\hline Copper alloys & CC $480 \mathrm{~K}$ & 2.1050 \\
\hline
\end{tabular}

Table 1. Material for additive manufacturing [1]

The powder for additive manufacturing can be made in several different ways. The manufacturing process depends on the powder material and its final quality. Gas atomization, VIM gas atomization, plasma atomization, electrode melting gas atomization and hydride-dehydride methods are the most commonly used for powder manufacture. None of these methods have $100 \%$ yield. Grains of incorrect size are separated from the powder. In general, the size of particles for laser sintering is set in the range of $15-45 \mu \mathrm{m}$, and for electron beam sintering in the range 45-106 $\mu \mathrm{m}$ [2]. Results from some of these methods are shown in Fig.1.

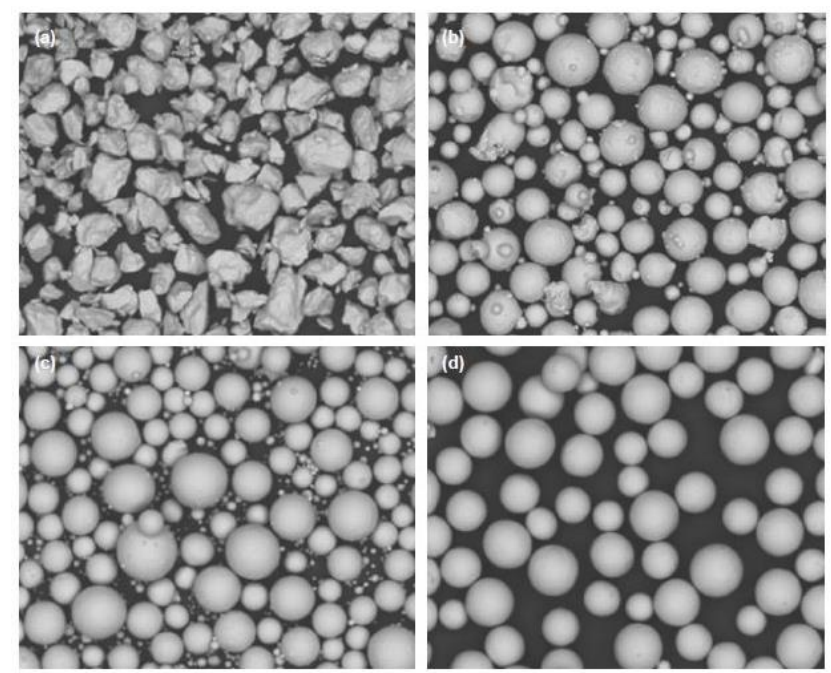

Fig. 1. SEM of typical particle shapes of Ti-6Al-4V powder for different manufacturing technologies - a) HDH; b) gas atomization; c) plasma atomization; d) rotating electrode atomization [3] 
Mechanical properties for one type of material may be different depending on the manufacturing technology used. Fig. 2 shows the yield strength and hardness for materials which are made in different ways [1].

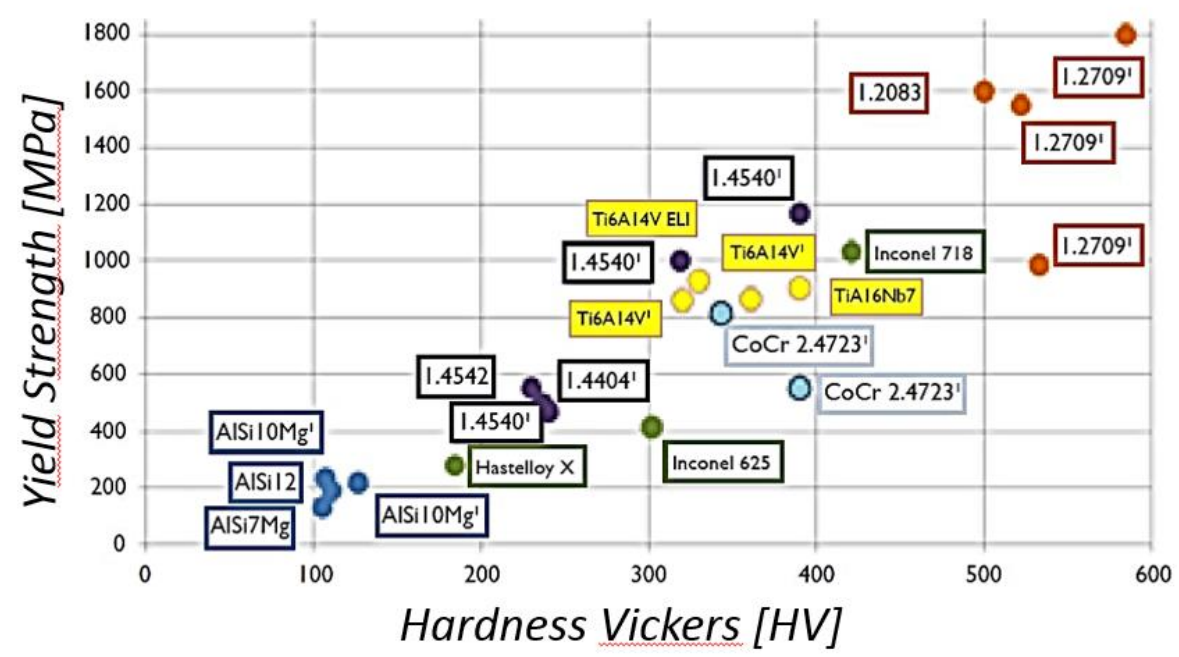

Fig. 2. Hardness and yield strength of materials used in additive technology $[1,2]$

The rate of cooling and the gas used for spraying influence the diameter of the produced particles and their microstructure, according to reference [1], see Fig. 3.

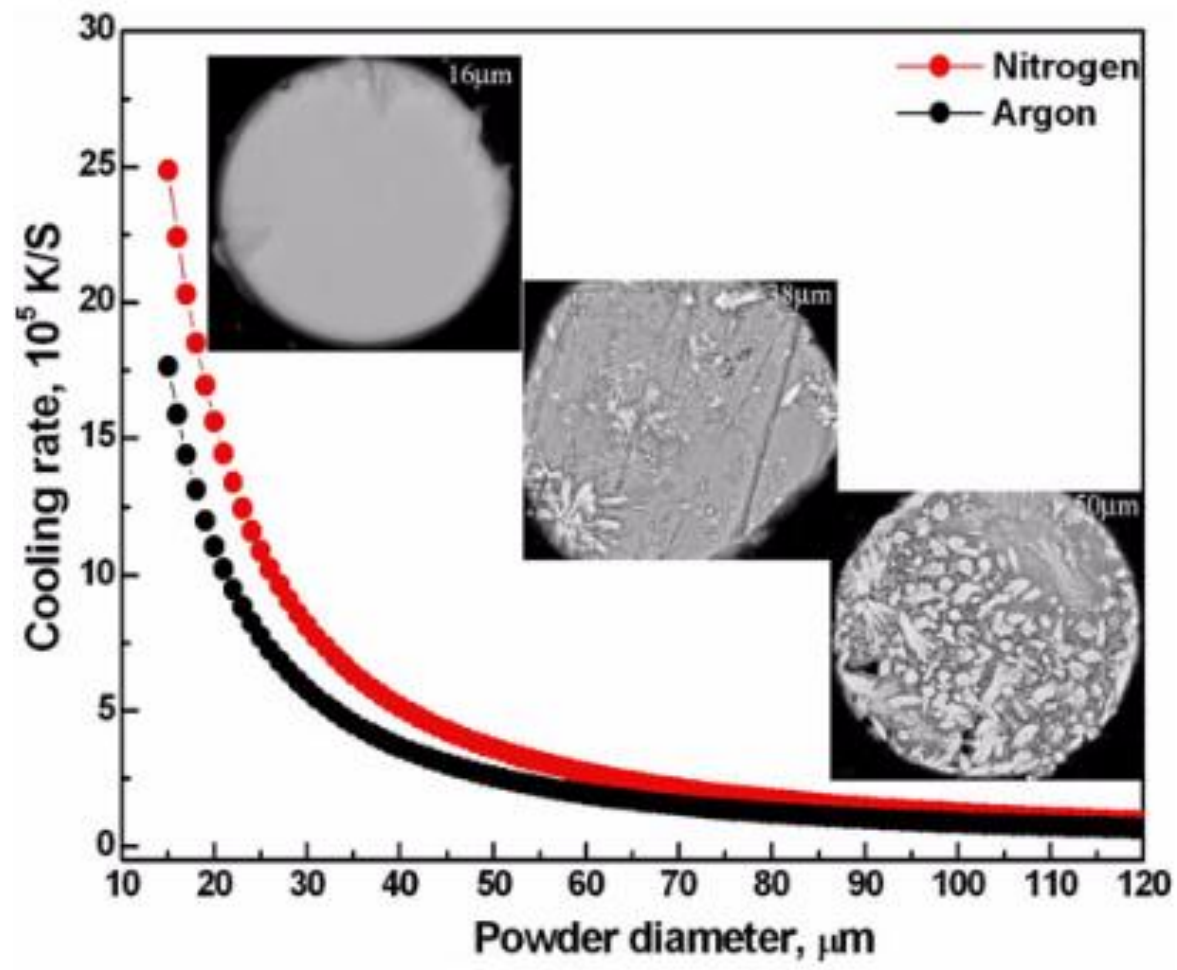

Fig. 3. Influence of cooling rate and type of atomizing medium on size and microstructure of powder $\mathrm{Al} 86 \mathrm{Ni} 6 \mathrm{Y} 4.5$ CO 2 La 1.5 [1]

Additive technology is increasingly being used in mechanical engineering and the number of publications in this area is growing as well. They are usually focus on the mechanical properties of the printed parts $[4,6]$ on to microstructure of the printed parts [5] but there is just basic information about the input material.

This paper is focused on the powder W-Nr.1.2709 (DIN X3NiCoMoTi18-9-5), on the evaluation of its shape and microstructure. It is usually used for plastic injection moulds, pressure casting of light metals, and cold pressing tools. The recommended chemical composition of printed and conventionally produced steels (hot formed) is shown in Tab. 2. Not much information has been found about this frequently-used powder. 


\begin{tabular}{|c|c|c|c|c|c|c|c|c|c|c|c|c|c|c|}
\hline & $\mathrm{C}$ & $\overline{\mathrm{Si}}$ & Mn & $\mathbf{P}$ & $\mathbf{S}$ & $\overline{\mathrm{Cr}}$ & Mo & $\mathbf{N i}$ & $\overline{V, W}$ & Co & $\mathbf{T i}$ & $\mathrm{Cu}$ & Al & $\mathbf{F e}$ \\
\hline MS1 & $\leq 0.03$ & $\leq 0.1$ & $\leq 0.1$ & $\leq 0.01$ & $\leq 0.01$ & $\leq 0.5$ & \begin{tabular}{c|}
4.5 \\
- \\
5.2
\end{tabular} & $\begin{array}{c}17.0 \\
- \\
19.0\end{array}$ & & $\begin{array}{c}8.5 \\
- \\
9.5\end{array}$ & $\begin{array}{c}0.6 \\
- \\
0.8\end{array}$ & $\leq 0.5$ & $\begin{array}{c}0.05 \\
- \\
0.15\end{array}$ & balance \\
\hline Conv. & $\leq 0.03$ & $\leq 0.1$ & $\begin{array}{c}\leq \\
0.15\end{array}$ & $\leq 0.01$ & $\leq 0.01$ & $\begin{array}{c}\leq \\
0.25\end{array}$ & $\begin{array}{c}4.5 \\
- \\
5.2\end{array}$ & $\begin{array}{c}17.0 \\
- \\
19.0\end{array}$ & - & $\begin{array}{c}8.5 \\
- \\
10\end{array}$ & $\begin{array}{c}0.8 \\
- \\
1.2\end{array}$ & - & - & balance \\
\hline
\end{tabular}

Table 2. Chemical composition of printed (MS1) and conventionally (Conv.) produced steel W-Nr. 1.2709

\section{Evaluation of the shape and microstructure}

The powder of steel W-Nr.1.2709 is supplied in 10 kilogram closed barrels. In general, it is necessary to observe the principles of safety at work, because some types of powders or their condensates may be self-inflammatory or explosive in combination with air [1]. A spherical shape is preferred due to good fluidity, but the manufacturer states that irregular particles do not reduce the quality of the final printed part [4].

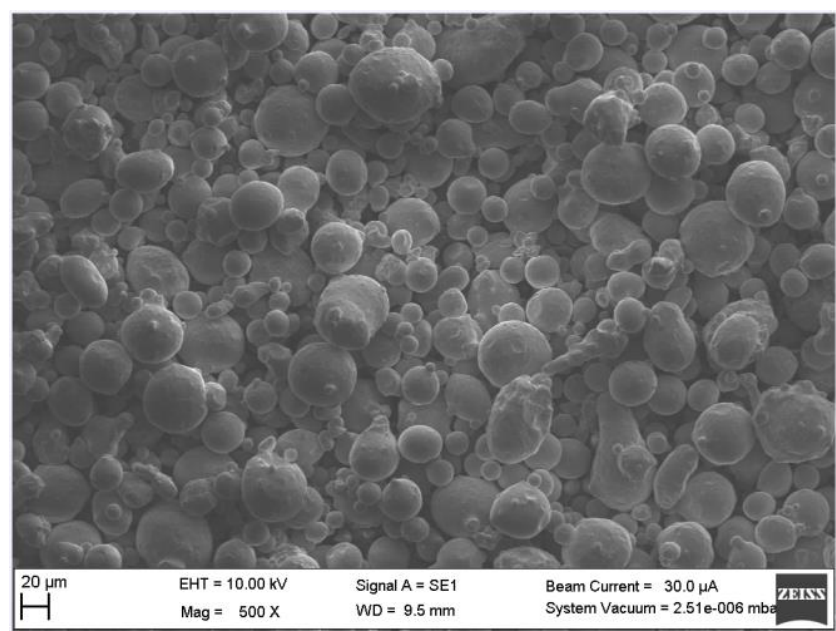

Fig. 4. SEM of powder W-Nr.1.2709

Firstly, it was necessary to determine the shape of the particles. Most of the grains are spherical and some are stuck together, see Fig. 5 This is the case for particles with similar and different sizes. This is because they were not divided before solid. This theory is confirmed below. It is possible to see two or more particles stuck together (Fig. 5 b), or a grain inside another grain. There is a minimal number of irregularly shaped particles in the powder. They probably did not arise during the production process, but during further manipulation. The peeling of layers (see below) or mutual contact of the grains cause the irregular shapes of the particles.

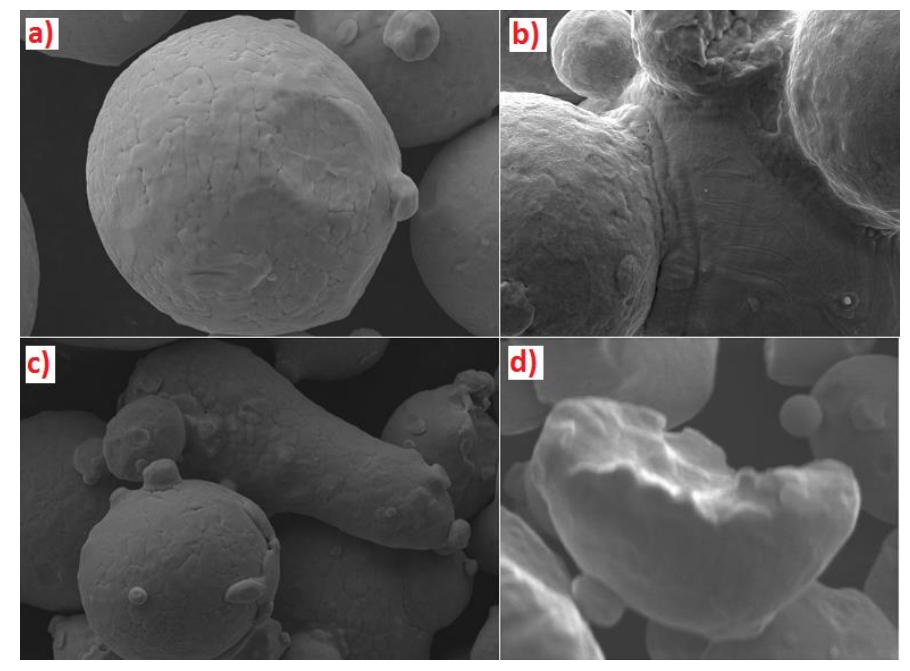

Fig. 5. Type of particles of the metal powder W-Nr. 1. a) spherical, b) several particles stuck together, c) elongated grain, d) irregular 
A unique flaky structure, or "elephant skin" can be seen on the surface of the grains. It is a question how this structure was created. A metallographic section provides the answer, shown in Fig. 6. The etched grains have a cellular/dendritic microstructure from the soft, tough solution. In general, dendrites are formed from the solution of crystallization with a negative temperature gradient. This arises during the manufacturing process when the metal alloy is melted and the gas is atomized to fine droplets. They are formed after solidification in individual grains of powders with a relatively stable chemical composition. Smaller grains contain slightly more Ni and Co. The dendrite borders contain slightly more Mo and $\mathrm{Ti}$ in comparison with the middle of the grain.

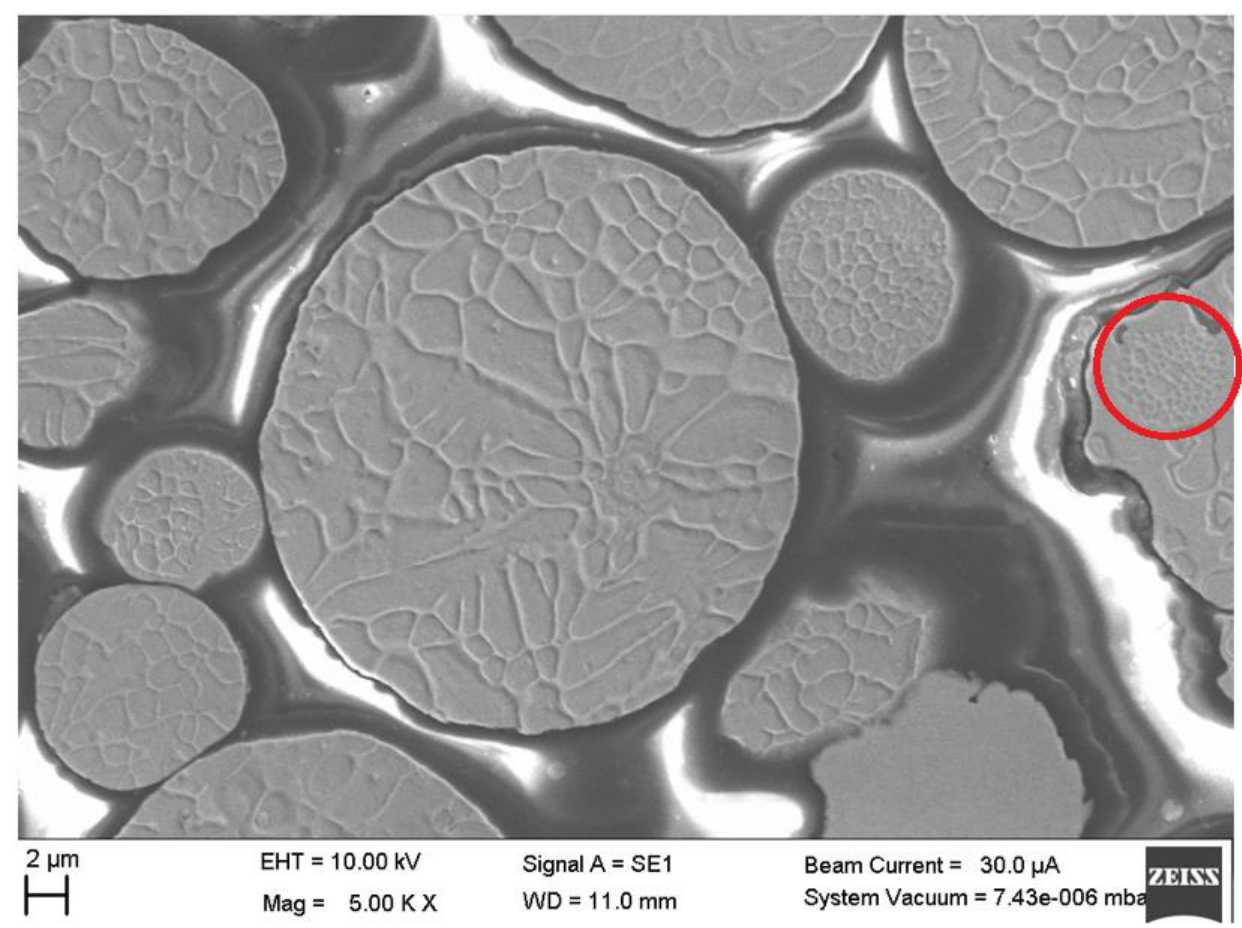

Fig. 6. Microstructure of powder W-Nr. 1.2709

Dendrites grow on the grain surface and create the characteristic "elephant skin" texture. The irregular growth of these grains stems from their production by gas atomization. In some cases, a grain grows inside another grain - Fig. 6 marked in red.

Fig. 7 shows particles stuck together. They contain more separate dendrites in one grain of irregular shape. This clarifies the theory of the formation of interconnected particles. Particles with a high portion of Fe and Ti were found in some grains (see Fig. 7, right)

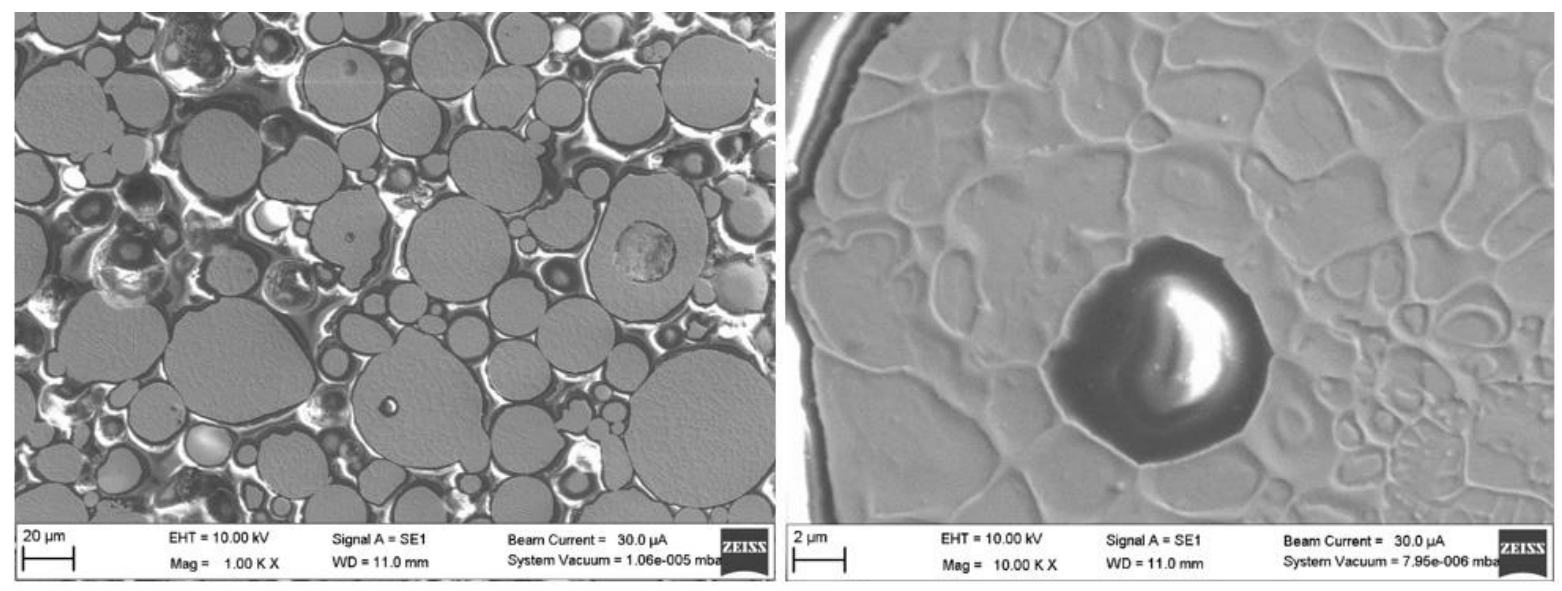

Fig.7. SEM of the microstructure

In the next step the powder which was used in the 3D print process was examined. This powder was not melted. It surrounded the printed component and was sieved back in the dispenser platform. A scan of this powder sample (see Fig 8) was compared with the new powder. 


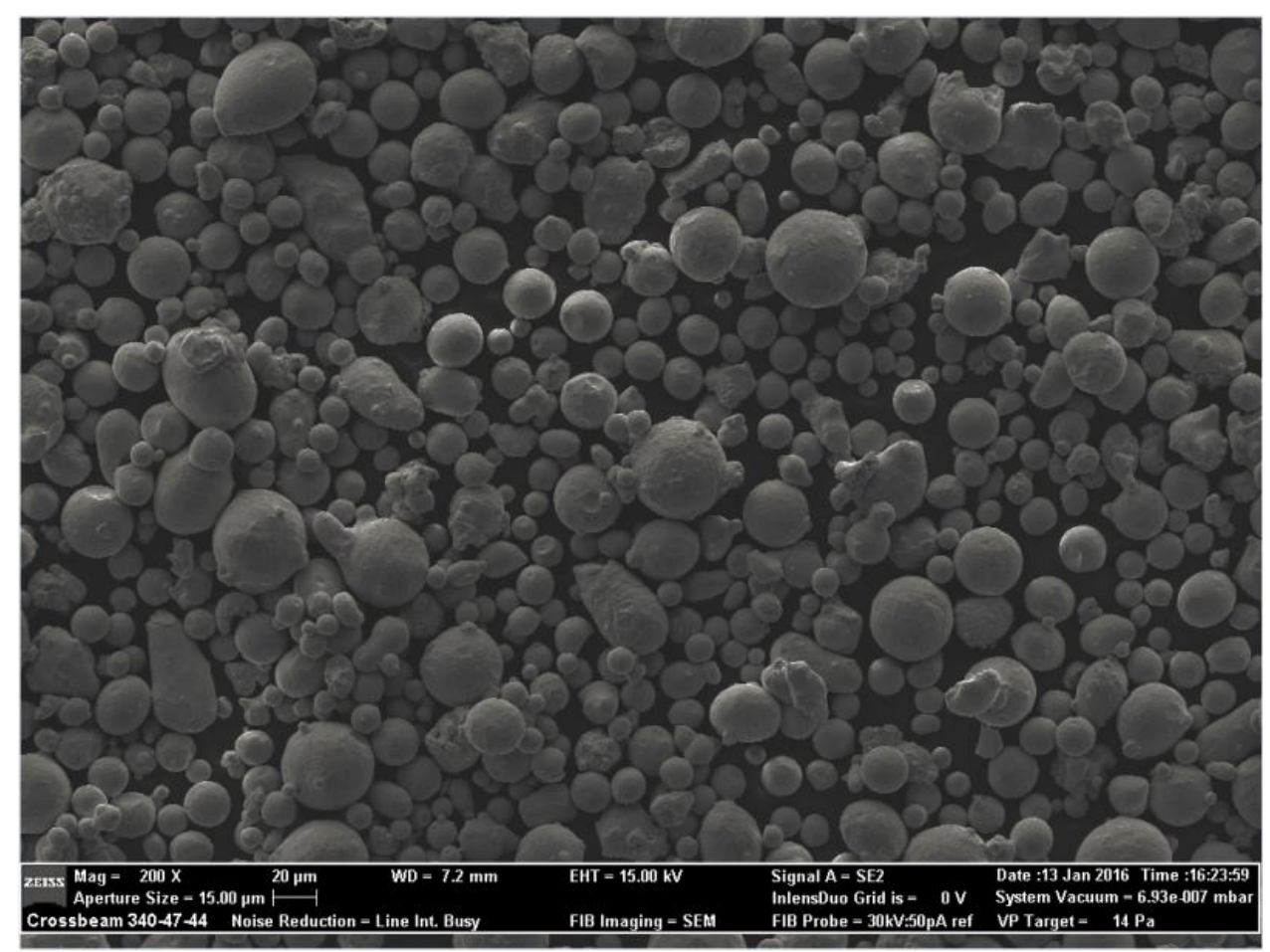

Fig. 8. Sieved powder

There were no visible differences between the new and the sieved powder. A very thorough investigation was made and a small percentage of powder particles without "elephant skin" was found. The surface of these particles was very smooth. They were not found in the new powder from any production batch, so this had to occur during the printing process.

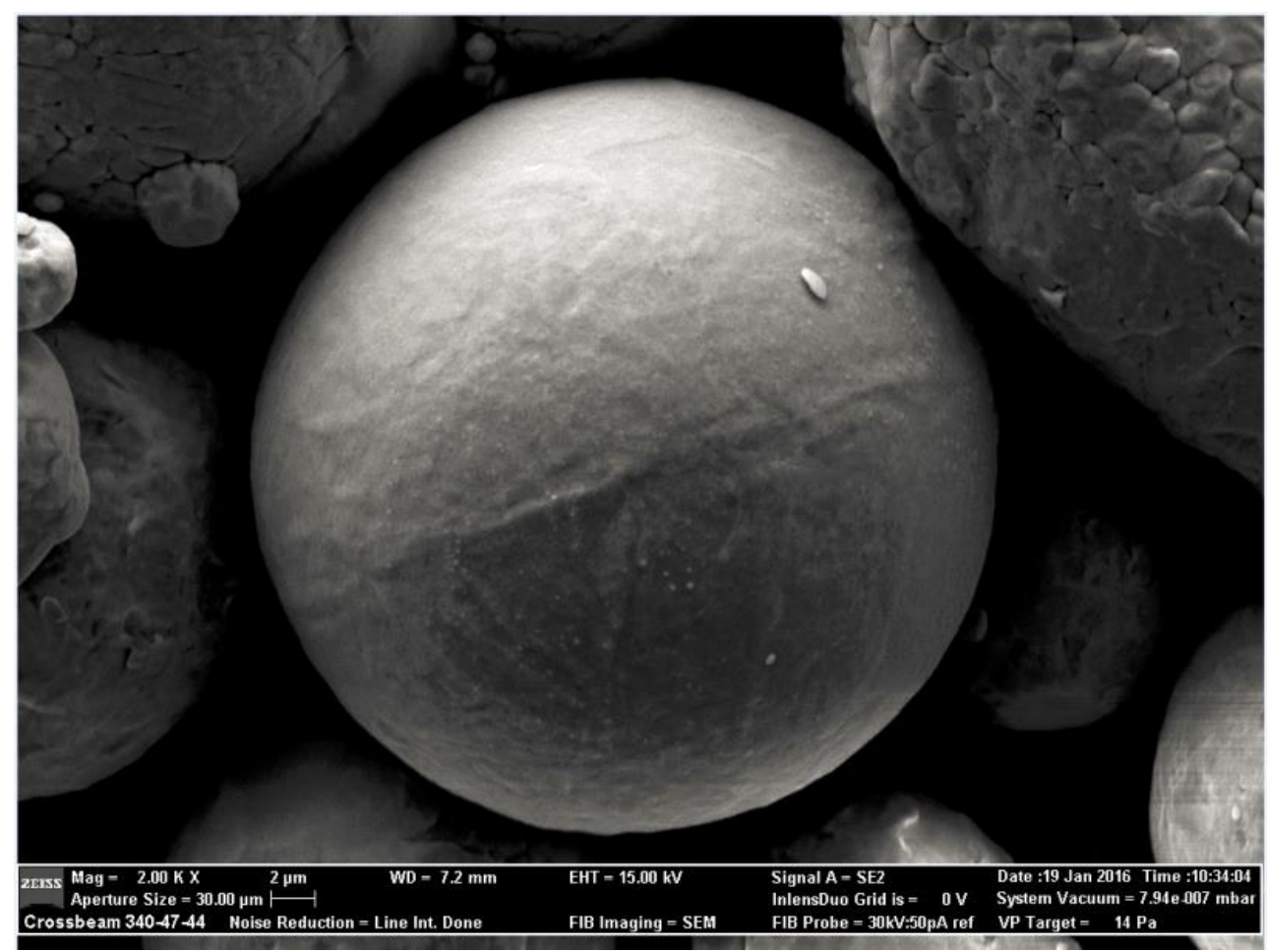

Fig. 9. SEM of the particles in the sieved powder

A metallographic section was made to compare this type of particle and particles from the new powder. The results are shown in Fig. 10. The grain has smooth surface. The dendrites do not grow to the surface, so the "elephant skin" cannot be seen. The chemical composition is comparable with the particles from the new powder. The question is, how these particles influence the mechanical properties of the printed parts. 


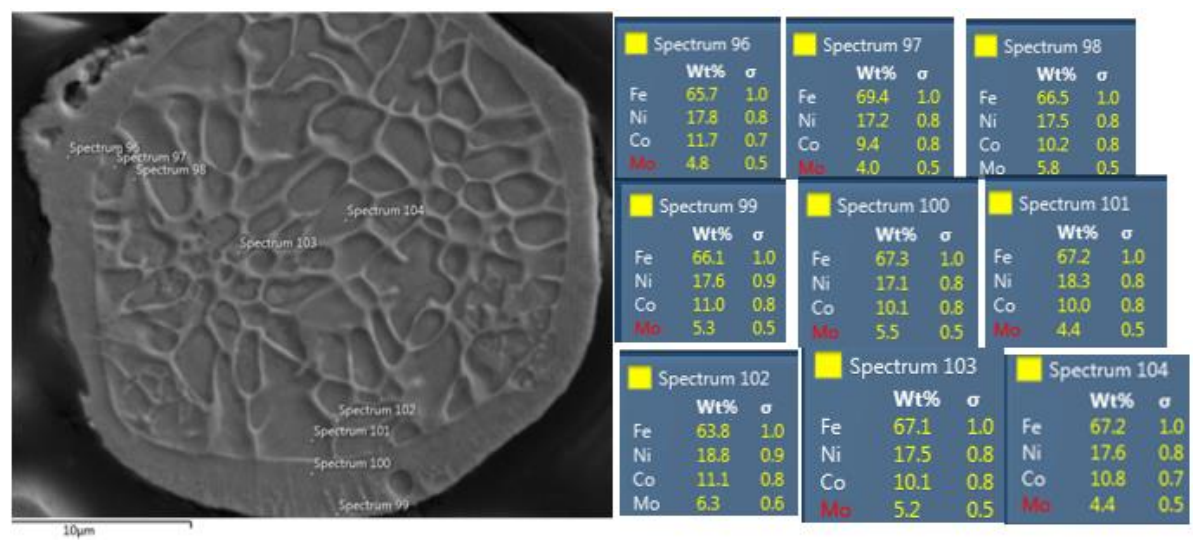

Fig. 10. Metallography of the particles in the sieved powder

The process of 3D printing was monitored by a high speed camera and a lot of particles were observed which are formed during the process. The metallographic section in Fig. 10 is completely unique. It has not been found in any other published scientific sources.

\section{Conclusion}

This paper was focused on the evaluation of metal particles of maraging steel W-Nr. 1.2709 according to their shape and structure. The new and used powder was observed after printing. The sieved powder was found to contain particles with the same chemical properties but with different structures on the grain surface. The dendrites form the basis for both types of particles. It was proved by using a high speed camera that smooth particles originate during the printing process. The next paper will describe how these particles influence the mechanical properties of the parts. There are scientific papers about metal powders for 3D printing, but there are none about the new particles which are formed in the printing process.

\section{Acknowledgments}

The article has been prepared under project LO1502 'Development of the Regional Technological Institute' under the auspices of the National Sustainability Programme I of the Ministry of Education of the Czech Republic aimed to support research, experimental development and innovation.

\section{References}

[1] Metal powders - the raw materials. Metal AM. (2015) . Available from: http://www.metal-am.com/introductionto-metal-additive-manufacturing-and-3d-printing/metal-powders-the-raw-materials/

[2] Introduction to Additive Manufacturing Brochure. (2015). Available from: http://www.epma.com/additivemanufacturing

[3] Dawes, J., Bowerman, R., Trepleton, R., Introduction to the Additive Manufacturing Powder Metallurgy Supply Chain. Johnson Matthey Technol. Rev., 2015, 59, (3), 243-256

[4] Daňa M., Zetková I., Hanzl P. Need for support structures depending on overhang size. In MM (Modern Machinery) Science Journal, December 2016. [online]. [cit. 2017-03-15]. Available from: http://www.mmscience.eu/content/file/archives/MM_Science_2016192.pdf

[5] Kucerova, L. Zetkova, I. (2016) Metallography of 3D Printed 1.2709 Tool Steel. In MANUFACTURING TECHNOLOGY. February 2016, Vol. 16, No.1. s. 140 -144. ISSN 1213-2489.

[6] Hanzl, P., Zetková, I., Mach J. Optimization of the pressure porous sample and its manufacturability by selective laser melting. Manufacturing Technology, 2017, roč. 17, č. 1, s. 34-38. ISSN: 1213-2489

[7] Rubešová, K., Jirková, H., Mašek, B. Vorel, I. (2016). Effect of Mini-Thixoforming Parameters on Microstructural Evolution in Low-Alloy Steel, Proceedings of the 26th DAAAM International Symposium, pp.0803-0809, pp.08030809, B. Katalinic (Ed.), Published by DAAAM International, ISBN 978-3-902734-07-5, ISSN 1726-9679, Vienna, Austria

[8] Cubrova, J[ana]; Vorel, I[van]; Vancura, F[ilip] \& Masek, B[ohuslav] (2016). Effect of Amount of deformation on Microstructure Evolution During Controlled Cooling of Forgings from FinishForging Temperature, Proceedings of the 26th DAAAM International Symposium, pp.0892-0896, B. Katalinic (Ed.), Published by DAAAM International, ISBN 978-3-902734-07-5, ISSN 1726-9679, Vienna, Austria DOI: 10.2507/26th.daaam.proceedings.124 